\title{
Collaborative interviewing in mathematical analogy technique (Part I): socialization in cognitive beavioural therapy Lefteris Konstandinidis*1, Thomai Lioura ${ }^{2}$, Dimitra Goga ${ }^{3}$, Nikos Papanikolaou ${ }^{1}$ and Nikolas Nikolaidis ${ }^{4}$
}

Address: ${ }^{1}$ Private Practice, Thessaloniki, Greece, ${ }^{2}$ Association for Mental Health and Social Rehabilitation (Epsica), Thessaloniki, Greece, ${ }^{3} 1$ st State Infant School, Athens, Greece and ${ }^{4} \mathrm{CMHC} /$ Central District of Thessaloniki, Greece

* Corresponding author

from International Society on Brain and Behaviour: 2nd International Congress on Brain and Behaviour

Thessaloniki, Greece. 17-20 November 2005

Published: 28 February 2006

Annals of General Psychiatry 2006, 5(SuppI I):S273 doi:I0.I 186/I744-859X-5-SI-S273

\section{Case Report}

Socialization of clients in CBT is an important task for therapists. In order to achieve an effective socialization procedure for clients starting CBT, we developed CLIMATE.

CLIMATE is an acronym for Collaborative Interviewing in Mathematical Analogy Technique. CLIMATE is a procedure based on the theories of ancient Greek scholars: i. Socrates, who introduced the dialectic method, ii. Plato, Socrates' best disciple who postulated the method of analysis and synthesis, iii. Aristotle, Plato's most known student and iv. Pappus of Alexandria, a great Greek geometer, who postulated the method of analysis and synthesis in mathematics. According to Plato, Socrates in order to prove to Menno that "all I know is that I know nothing" used a mathematical paradigm to an illiterate servant boy. When socializing a patient into CBT using CLIMATE the therapist follows a similar process.

CLIMATE is a step-by-step analysis and synthesis procedure using a mathematical analogue example. Socratic questioning is used extensively and the therapist has the opportunity to explain what collaborative empiricism is. CLIMATE, being highly structured, uses a set of 15 specific steps comprised of a series of sequential questions that the therapist asks the client to guide him or her to problemspecific and process-specific concrete answers. It takes approximately 20 minutes to complete and it has been applied to a sample of more than 500 patients.

The therapist applies CLIMATE at the end of the first session, after the client's history has been reviewed. At the initial stage of CLIMATE the therapist makes clear three important data: i. the nature of the client's request, ii. whether the client believes that his or her problem can be solved and iii. what the client has already done to solve his or her problem. After that the therapist continues this technique leading the patient to think and to state by himself what is necessary for his problem and also to understand what CBT is.

\section{References}

I. Blenkiron P: Stories and analogies in cognitive behaviour therapy: a clinical review. Behavioural and Cognitive Psychotherapy 2005, 33:45-49.

2. Polya G: How to solve it 2nd edition. Princeton University Press; 1957.

3. Burns GW: 101 Healing Stories, using metaphors in therapy. Wiley 2001. 